\title{
Validation of the Persian version of the Elderly Vulnerability to Abuse Screening Scale (VASS)
}

\author{
SAEIDEH MOTAHEDI 1, A, B, E, F, MAHBOOBEH KHAJEH ${ }^{2, \text { A, E, F }, ~ A H M A D ~ K H O S R A V I ³, ~ A, ~ c, ~ D, ~ E ~}$ \\ ORCID ID: 0000-0001-9326-3376 ORCID ID: 0000-0002-0684-9481 ORCID ID: 0000-0002-1106-3782 \\ SEYEDMOHAMMAD MIRHOSSEINI ${ }^{4, \mathrm{~B}, \mathrm{E}, \mathrm{F}}$, HOSSEIN EBRAHIMI5, A, E, F \\ ORCID ID: 0000-0002-2087-0164 \\ ORCID ID: 0000-0001-5731-7103
}

\author{
${ }^{1}$ Student Research Committee, School of Nursing and Midwifery, Shahroud University of Medical Sciences, \\ Shahroud, Iran \\ ${ }^{2}$ School of Nursing and Midwifery, Shahroud University of Medical Sciences, Shahroud, Iran \\ ${ }^{3}$ Department of Epidemiology, Center for Health Related Social and Behavioral Sciences Research, Shahroud \\ University of Medical Sciences, Shahroud, Iran \\ ${ }^{4}$ Student Research Committee, School of Nursing and Midwifery, Mashhad University of Medical Sciences, \\ Mashhad, Iran \\ ${ }^{5}$ Center for Health Related Social and Behavioral Sciences Research, Shahroud University of Medical Sciences, \\ Shahroud, Iran
}

A - Study Design, B - Data Collection, C - Statistical Analysis, D - Data Interpretation, E - Manuscript Preparation, F - Literature Search, G - Funds Collection

Summary Background. Elderly abuse is a major problem in developing countries and causes complications such as reduced quality of life, increased incidence of mental diseases and even death.

Objectives. To evaluate the validity of a Persian version of the Vulnerability Abuse Screening Scale (VASS) in the elderly.

Material and methods. This methodological study was performed on 200 older adults (aged $\geq 60$ ) in Iran. Measurements included the Elderly Vulnerability to Abuse Screening Scale (VASS), Mini-Mental State Examination (MMSE) and Abbreviated Mental Test Score (AMTS).

Results. The mean and standard deviation of the studied population was $68 \pm 5.8$ years. After applying the necessary changes in the items at the face and content validity stage, the initial reliability was confirmed in a sample of 50 elderly with a Cronbach's alpha coefficient of 0.74 . The initial tool model (12-question version) was not validated in the factor analysis process, so the second tool model (9-question version) was prepared and found to have construct validity. Cronbach's alpha coefficient in the 9-question version was 0.70 , and the intra-class correlation coefficient was 0.99 .

Conclusions. According to the study results, it seems that the Persian 9-question version can be used as a valid and reliable tool in the study and assessment of vulnerability to abuse in the Iranian elderly population.

Key words: abuse, elder, Validation Vulnerability Abuse Screening Scale, VASS, Iran.

Motahedi S, Khajeh M, Khosravi A, Mirhosseini S, Ebrahimi H. Validation of the Persian version of the Elderly Vulnerability to Abuse Screening Scale (VASS). Fam Med Prim Care Rev 2021; 23(2): 196-202, doi: https://doi.org/10.5114/fmpcr.2021.105923.

\section{Background}

According to the report of the World Health Organization (WHO), between 2015 and 2050, the proportion of the world's elderly population will increase from $12 \%$ to $22 \%$ [1]. In other words, the number of elderly in 2015 was 900 million and will increase to 2 billion by 2050 [2]. In 2015, in Iran, the population of those 60 years old and above was $8 \%$ of the total population and is projected to reach $31 \%$ by 2050 , amounting to 29 million of the total population of 92 million [3]. Aging is considered as a natural and inevitable biological process. This phenomenon causes many changes in the health and social functioning of individuals. Different factors are involved in causing these changes and cannot be considered a specific factor in causing adverse effects [4].

One of the social problems of the elderly is abuse. According to the definition of the National Research Council (United States), elder abuse involves as actions that cause harm or create a serious risk of harm to a vulnerable elder by a caregiver or other person who stands in a trust relationship to the elder. In research, approximately 1 out of every 10 elderly individual has been abused. Abuse of the elderly is predicted to increase as the aging trend of the population increases [5]. The prevalence of this problem in developing countries is estimates at $13.5 \%$ to $50.3 \%[6-8]$.

In a study conducted based on the evidence of 52 studies in 28 different countries in 2017, including 12 low- and middle-income countries, it was found that $15.7 \%$ of people 60 years old and older had been abused over the past year. This is likely to be the lowest level considered, and the true incidence of this phenomenon is unclear, as it is estimated that only 1 out of every 24 cases of elderly abuse is reported. The reason is that older people are often afraid of reporting cases of abuse to family, friends or organizations [2]. In another study from Fars Province, Iran, at least a quarter of the elderly experienced abuse [9]. Elderly abuse is associated with neglect, exploitation, depression, cognitive impairment, loss of function and increased mortality. While, according to the National Center for Elderly Abuse in the United States, 1 in every 10 American adults is abused, only 1 out of 14 cases is reported $[10,11]$. By using a structured review and meta-analysis, Molaei et al. reported an overall prevalence 


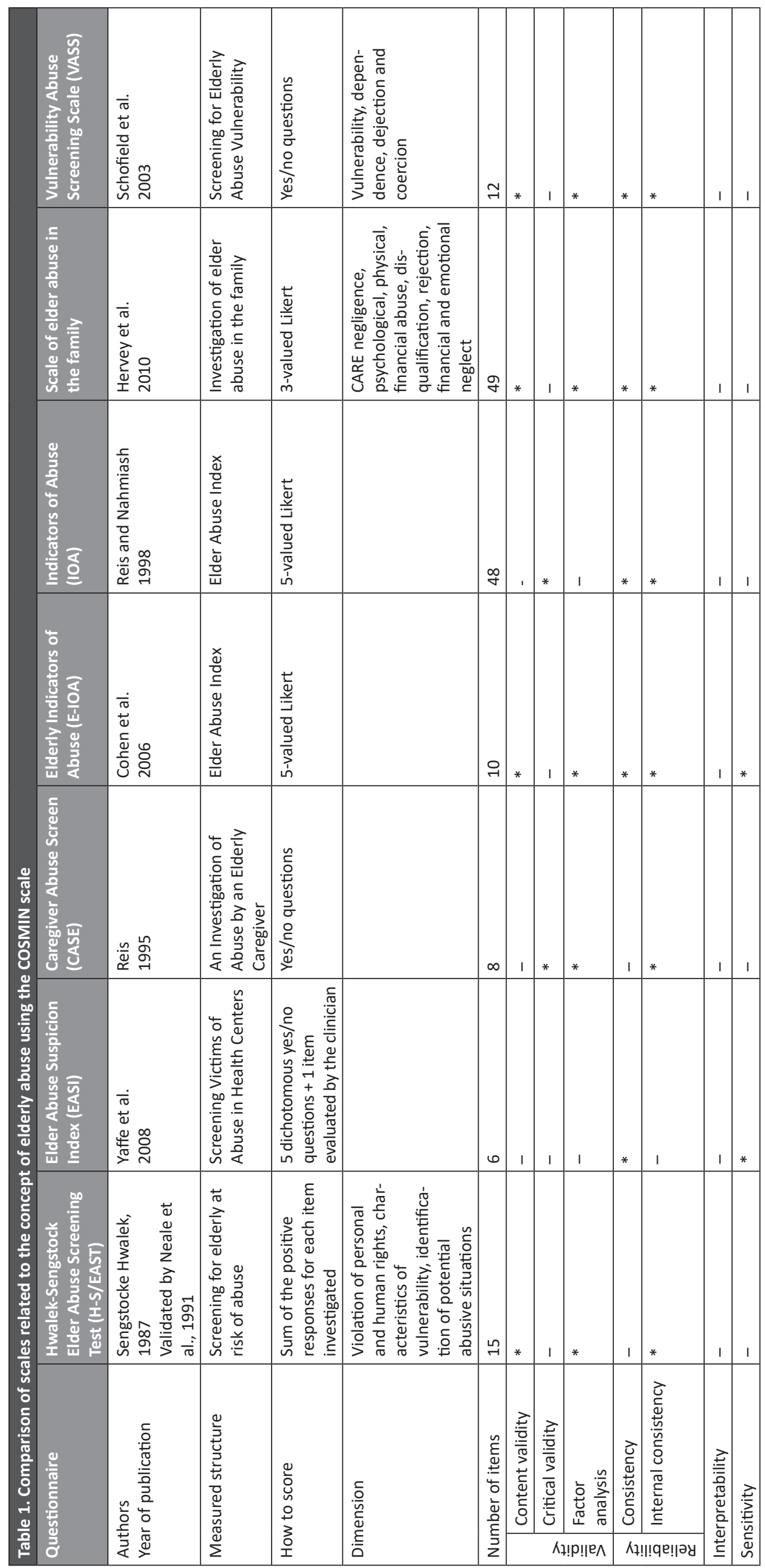


of elderly abuse in Iran at $56.4 \%$, which is significantly higher than studies in other countries, despite the same definition of elderly abuse [12]

This problem is a form of violence and a manifestation of human rights abuses and includes physical, sexual, emotional, financial and material abuse, abandonment, neglect and loss of dignity and respect. The report indicated $11.8 \%$ psychological abuse, 3.8\% financial abuse, $4.1 \%$ neglect, $1.9 \%$ physical abuse and $2.2 \%$ sexual abuse [13]

The phenomenon of elderly abuse is a major problem in developed and developing countries at all levels of the community, both rich and poor [14]. Different problems, such as financial dependency on children, low literacy level and gender, are considered as risk factors [15]. The adverse consequences of elderly abuse include reduced quality of life, reduced security, as well as increased incidence of diseases, aggression, learned helplessness, mental disorder and death $[9,16-18]$.

Regarding the increasing prevalence of elderly abuse, as population growth continues to increase and the majority of victims remain unidentified and preventable, unlike elderly diseases, regular screening at the community level, health centers, medical offices and elderly welfare services is very important and helpful $[19,20]$. In this regard, there are various tools for assessing elderly abuse that are presented in Table 1 based on the COSMIN criteria checklist [21].

In Iran, few studies have been conducted in this field. For example, the design and psychometric evaluation of the Elderly Vulnerability to Abuse Screening Scale (VASS) in the family was conducted by Heravi-Karimooi et al. with 49 items [22]. This questionnaire has good validity and reliability, but it also has some limitations, including: the large number of items and the length of the questionnaire and the need to spend 20 minutes to complete. Moreover, it is not appropriate with the physical and mental conditions of the elderly, and in some cases, given the cultural conditions of Iranian society, many unrealistic answers may be given to its items. As shown in Table 1, one of the appropriate tools in this field is the VASS [23].

The VASS with 12 items and 4 sub-scales (vulnerability, dependency, depression and threat) was designed by Schofield et al. (2003), based on the Hwalek Sengstock/Elder Abuse Screening Test (HS/EAST) questionnaire in Australia, and its validation characteristics on a population of 12,000 elderly individuals were evaluated in a cohort study. The tool is a self-report using indirect questions and can be completed in 5 minutes. The answers to the questions are yes/no and easily scored. The advantages of this tool include the identification of unknown cases of injury and the possibility of screening the elderly in the community. This questionnaire also has a small number of questions, consistent with the elderly's physical and mental condition, and an elderly individual can answer all questions with sufficient precision within the 5 minute timespan. The questions indirectly address abuse, and the elderly can easily respond to them even in the presence of others, especially their family members. Due to the simplicity of the questions of the tool, it is not necessary to complete it with an expert or trained person $[23,24]$. This tool has been translated and validated in several countries, including: Turkey, France, Portugal and Brazil [25-31]. In addition, a number of studies have used this tool to identify elderly abuse [32-41]. Regarding the increasing elderly population and the high prevalence of abuse, as well as the need to identify those at risk due to many victims being unknown, a reliable native tool is essential to provide preventive services and address this problem.

\section{Objectives}

Among the existing tools based on the above, as well as the positive characteristics of the VASS, this study was designed and conducted to validate the Persian version of the VASS to be used in future research as a valid tool for screening elderly abuse.

\section{Material and methods}

\section{Validity assessment}

This paper is the result of a methodological study of tool validation. 200 elderly over 60 years of age were selected by simple random sampling from the elderly covered by Shahroud health centers from March to September in 2019. The inclusion criteria were those 60 years of age and over, a 24 and above score in the Mini Mental State Examination (MMSE) for educated people [42] and scores of 7 and above in the Abbreviated Mental Test Score (AMTS) for illiterate people [43], and the exclusion criteria were severe physical diseases (which could disrupt the process of completing the questionnaires).

First, after obtaining permission from the researcher, based on the standard English version protocol of validation [44], the screening scale for VASS was translated by two Persian translators (forward translation); the first was an expert in the field of medical science with regard to the target group (the elderly), and the second was an English to Persian translation specialist. The translations and original versions of the tool were then reviewed by a research team with a panel of five experts. At the retranslation (backward translation) stage, it was again translated into English by two other translators who had no knowledge of the original text of the tool. This identified potential conflicts between the two translation groups and extracted suggestions from each of the translators on the more culturally appropriate new version. The resulting version was re-examined by a panel of experts, and an initial draft of the tool was prepared. In this study, face validity was performed in two ways, qualitatively and quantitatively, and to determine face validity qualitatively, 15 elderly individuals were interviewed face to face and were asked to complete each item in terms of the level of difficulty, relevancy and ambiguity and provide their suggestions. In order to determine the quantitative face validity of the questionnaire, the item impact score was calculated. If the impact of an item was equal to or greater than 1.5, it was maintained in the tool; otherwise, it was eliminated. In addition, expert opinions were used to confirm the face validity of the items [45].

The content validity was then checked qualitatively and quantitatively. It should be noted that due to the changes that occurred in the content validation process, after content validity, face validity was re-examined with the help of the target group.

In order to determine the content validity of the tool in a qualitative manner, experts in scientific tool design and nursing and individuals with experience in instrumental and nursing studies were asked to review the tool based on grammar criteria, use of appropriate words, items in their proper place and appropriate scoring. The content validity ratio (CVR) and content validity index $(\mathrm{CVI})$ were used for quantitative content validity [46]. According to the Lawshe table, to determine the minimum value of the content validity ratio index, expressions with a CVR value greater than 0.49 (based on 14 expert evaluations) were significant and retained [47]. CVI was then calculated based on the Waltz and Bausell content validity index [48]. The minimum acceptable value for CVI was equal to 0.79 [46].

\section{Primary reliability}

After determining the face and content validity, the primary reliability of the questionnaire was assessed by an internal consistency method by calculating Cronbach's alpha coefficient in a sample of 50 elderly people. The minimum acceptable level of alpha was considered as 0.7 . The stability or reliability of the tool over time was also confirmed by a two-week test/retest, and the intra-class correlation index was evaluated [49].

\section{Confirmatory factor analysis}

In order to determine the construct validity of the tool, factor analysis is performed in two ways: exploratory and confirma- 
tory. If the tool is made for the first time, and there is no initial hypothesis about its dimensions, exploratory factor analysis is used. However, in cases where items are identified based on dimensions, such as the present study, the confirmatory method is used [50].

The confirmatory factor analysis process was performed as follows.

For the number of samples, there is no general agreement among experts, varying from 3 to 10 samples per item [50].

In this study, considering 10 samples for each item, 120 samples were first considered, which was increased to 200 samples after performing the Kaiser-Meyer-Olkin Measure of Sampling Adequacy (KMO) and Bartlett's test of sphericity. In the KMO test, values of 0.7 and higher are acceptable, and in Bartlett test, values of 2 and less are acceptable [51]

\section{Secondary reliability}

The secondary reliability of the tool was determined by calculating the intra-class correlation coefficient.

\section{Ethical consideration}

In order to adhere to the ethical principles, the purpose of the research and confidentiality of information was explained to the participants, and informed written consent was obtained. The study was approved by the ethics council of the Shahroud University of Medical Sciences under code: IR.SHMU. REC.1397.079.

\section{Results}

The mean and standard deviation of age was $68 \pm 5.8$ years. The demographic characteristics are presented in Table 2 .

\begin{tabular}{|c|c|c|c|}
\hline \multicolumn{2}{|c|}{ Demographic characteristics } & \multirow{2}{*}{$\begin{array}{l}\text { Frequency } \\
88 \\
112 \\
\end{array}$} & \multirow{2}{*}{$\begin{array}{l}\text { Percentage } \\
44 \\
56\end{array}$} \\
\hline Gender & $\begin{array}{l}\text { female } \\
\text { male }\end{array}$ & & \\
\hline Marital status & \begin{tabular}{|l|} 
single \\
married
\end{tabular} & \begin{tabular}{|l|}
57 \\
143 \\
\end{tabular} & $\begin{array}{l}28.5 \\
71.5 \\
\end{array}$ \\
\hline Employment & $\begin{array}{l}\text { retired } \\
\text { self-employed } \\
\text { worker } \\
\text { unemployed } \\
\text { housewife } \\
\end{array}$ & $\begin{array}{l}82 \\
33 \\
13 \\
4 \\
68 \\
\end{array}$ & $\begin{array}{l}41 \\
16.5 \\
6.5 \\
2 \\
34 \\
\end{array}$ \\
\hline $\begin{array}{l}\text { Accompanying the } \\
\text { elderly }\end{array}$ & $\begin{array}{l}\text { single } \\
\text { with wife } \\
\text { with child } \\
\text { with child and } \\
\text { wife } \\
\end{array}$ & \begin{tabular}{|l|}
48 \\
123 \\
9 \\
\\
20 \\
\end{tabular} & $\begin{array}{l}24 \\
61.5 \\
4.5 \\
\\
10 \\
\end{array}$ \\
\hline Housing & \begin{tabular}{|l} 
personal \\
rental
\end{tabular} & \begin{tabular}{|l|}
182 \\
18 \\
\end{tabular} & $\begin{array}{l}91 \\
9 \\
\end{array}$ \\
\hline Insurance & $\begin{array}{l}\text { have } \\
\text { have not }\end{array}$ & $\begin{array}{l}195 \\
5\end{array}$ & $\begin{array}{l}97.5 \\
2.5\end{array}$ \\
\hline \multirow[t]{2}{*}{$\begin{array}{l}\text { Complimentary } \\
\text { insurance }\end{array}$} & $\begin{array}{l}\text { have } \\
\text { have not }\end{array}$ & $\begin{array}{l}128 \\
72\end{array}$ & $\begin{array}{l}64 \\
36\end{array}$ \\
\hline & \multicolumn{3}{|c|}{ Mean (standard deviation) } \\
\hline Age & \multicolumn{3}{|l|}{$68.06 \pm 5.8$} \\
\hline $\begin{array}{l}\text { Successful aca- } \\
\text { demic years }\end{array}$ & \multicolumn{3}{|l|}{$7.40 \pm 4.9$} \\
\hline Number of children & \multicolumn{3}{|l|}{$3.95 \pm 1.6$} \\
\hline
\end{tabular}

In this study, face validity was confirmed qualitatively and quantitatively. In order to resolve ambiguity, a tangible example was added to question 4 , with suggestions from 10 participants at this stage, and question 6 was changed from "Can you take your medication and take it with you?" to "Are you allowed to take your own medicines and bring them with you?", and question 10 was changed from "Does anyone in your family make you stay in bed or tell you you're sick while you know you're not sick?" to "Does someone in your family make you stay in bed or tell you are sick while you know you are okay?"

In order to determine the significance of each expressions, the impact item score was calculated. All questions scored above 1.5 and were acceptable. In determining content validity, CVI and CVR were 0.79 and 0.49 , respectively, for all questions. At this stage, no change was made to the questionnaire structure.

In order to determine the construct validity, considering the one-dimensionality of VASS and not changing or removing any questions during the forward and backward translation stages and using a confirmatory factor analysis based on the structural equation model, the construct validity of the questionnaire was then assessed in the present community.

The KMO sampling adequacy index in this model was equal to 0.717 , indicating the adequacy of the samples for factor analysis. Bartlett's test of sphericity was also significant at $p<0.001$ and showed a sufficient correlation between the questionnaire questions for performing factor analysis.

First, a factor analysis was performed with a 12-item model of the questionnaire. The results showed that this model of measuring abuse did not have a good fit, and some numbers and parameters of the model were not significant (Figure 1).

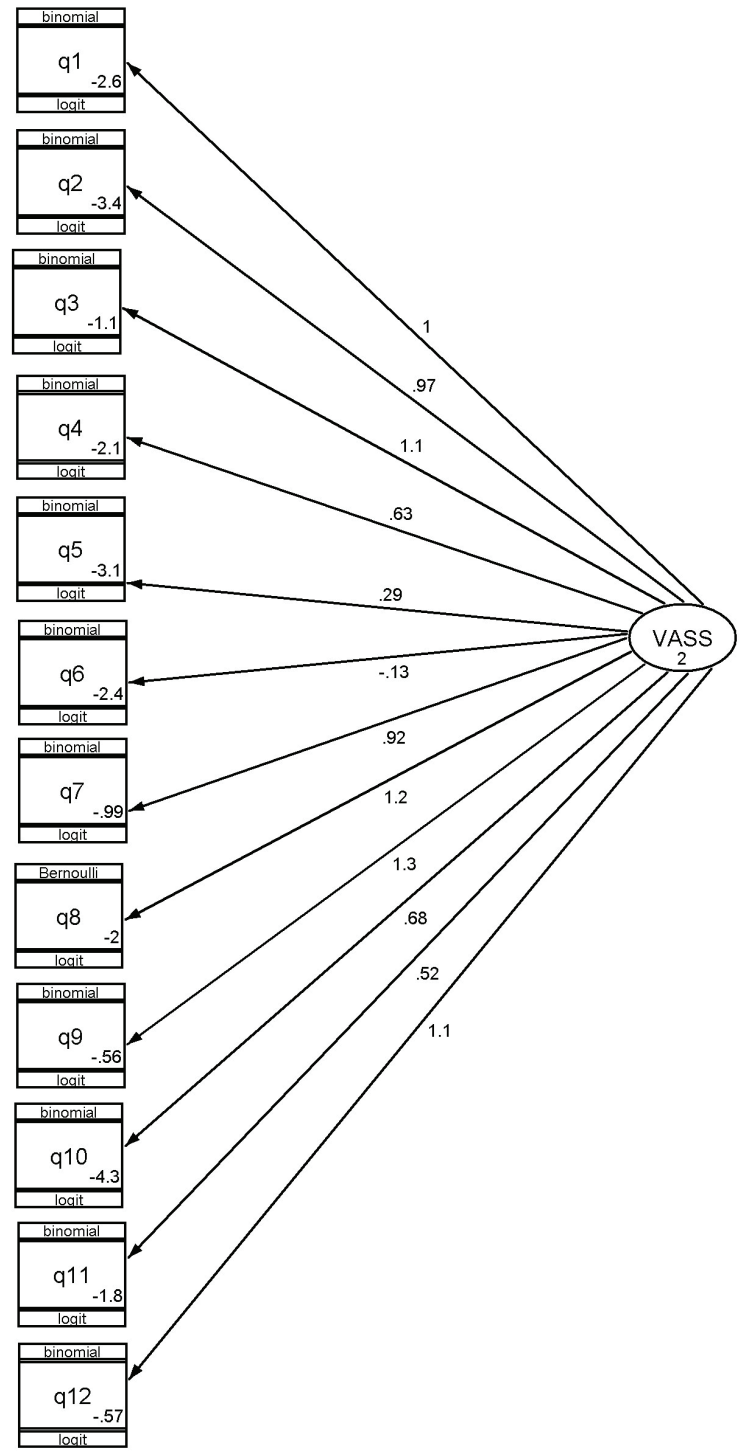

Figure 1. 12-item factor analysis of the questionnaire 
In the first model, items 5, 6 and 10 had a variance close to zero, which was not significant $(p<0.05)$ and was not confirmed in factor analysis. Therefore, according to the results and re-examination of these items, factor analysis was performed by removing the mentioned items with the 9-question version, and thus the structure validity was confirmed with the second model.

After factor analysis, Akaike Information Criterion (AIC) [52] and Schwartz-Bayesian Information Criterion (BIC) [53] fitness indices and degree of freedom were calculated. The values of fitness and freedom indices in the second model decreased compared to the first model, which indicates the relative and reasonable fit of the second model. The results are shown in Table 3.

\begin{tabular}{|c|c|c|}
\hline $\begin{array}{l}\text { Goodness of Fit Index } \\
\text { (GFI) }\end{array}$ & $\begin{array}{l}\text { 12-question } \\
\text { version }\end{array}$ & $\begin{array}{l}\text { 9-question } \\
\text { version }\end{array}$ \\
\hline AIC & $1,938.1$ & $1,701.1$ \\
\hline BIC & $2,017.2$ & $1,760.5$ \\
\hline Degrees of freedom (dfP) & 24 & 18 \\
\hline
\end{tabular}

Finally, the internal consistency method (Cronbach's alpha) and intra-class correlation (test-retest) were used to evaluate the secondary reliability. Cronbach's alpha coefficient for the whole questionnaire before the removal of three items was equal to 0.67 , and after the removal of three items, it was equal to 0.70 . The correlation coefficient within the categories was 0.99 , which is desirable. Thus, after removing the three items (5, 6 and 10 ), this questionnaire was of acceptable reliability. These results can also confirm the proper construct validity of the tool.

The cut-off point in the 12-question version was equal to $1 / 4$ of the number of questions, i.e. a score of 3 or more. Accordingly, in the 9-question version, a cut-off point of 2.25 was considered.

\section{Discussion}

According to previous studies, in some cases, researchers have used researcher-made tools or multiple questions [15]. Using tools with no validation does not provide accurate information. Although Heravi-Karimooi et al. designed a tool to measure elderly abuse in the family [22], due to the length of above-mentioned tool, we sought out a shorter version for screening abuse in this study, which was designed and conducted with the aim to validate the Persian version of the elderly VASS.

In the initial stage, the necessary measures for formal validity were taken quantitatively and qualitatively. For content validity, all items were retained after calculating the content validity ratio and index. The construct validity was then confirmed by confirmatory factor analysis to investigate the factor structure of the questionnaire. In the first model for factor analysis of the 12-question version, items 5, 6 and 10 had near zero variance and were not confirmed in factor analysis. Referring to these items, it can be concluded that given the culture of the Iranian people in trusting their family members in most cases, most people's positive response to item 5 (Do you have full trust in the majority of your family members?) is possible. The elderly's strong attachment to the family in various aspects of life has also created trust. Since family members are those closest and most accessible to the person, and the elderly spend most of their time with them, as a result, they have complete trust in them. For item 6 (Are you allowed to take your own medicines and bring them with you?), since elderly individuals with dementia were not included in the study, it is natural that the subjects were able to maintain and take their medications, many elders prepare and use their own medications in normal or emergency situations, and busy families do not take this responsibility. For item 10 (Are you forced by your family to stay in bed when you are not sick?), in Iranian culture, elders usually consider staying in bed as a disability and usually refuse to do so. In the next stage, factor analysis was performed with the 9-question model again, and thus construct validity was confirmed. Lastly, internal consistency (Cronbach's alpha) and intra-class correlation (test/ /retest) were used to study final reliability. Cronbach's alpha coefficient was 0.70 , and the intra-class correlation coefficient was 0.99 , which was desirable. In a similar case in a study by Schofield and Mishra, two items were first added to a modified $\mathrm{H}-\mathrm{S} / \mathrm{EAST}$ questionnaire, and at the construct validity stage, after performing factor analysis, five items were removed from the modified questionnaire, which resulted in the creation of the VASS. In this study, Cronbach's alpha coefficient varied from $31 \%$ to $74 \%$ for the four subscales [23], which is consistent with our study.

In a study in Portugal, Rodrigo da Silva Maia et al. reported a KR-20 value of 0.58 , and a KR-20 value of 0.68 was reported in a Brazilian study $[29,30]$, which indicates the moderate reliability of these tools, while Cronbach's alpha coefficient in the present study was reported at 0.70 , indicating a high reliability.

In 2016, a VASS validation study was conducted on 140 elderly individuals over 65 years of age who referred to the general clinic. The study inclusion criteria included speaking Turkish, no dementia or mental diseases. In this study, face validity, content validity and construct validity were confirmed, and Cronbach's alpha was generally reported above 0.70 , which is consistent with the present study [25].

The Elderly Abuse Suspicion Index (EASI) was validated by Yaffe et al. in Canada. This questionnaire deals with the screening of those elderly referring to treatment centers and should be verified by a doctor of medicine (MD) after an elderly clinical examination and with findings such as poor eye contact, malnutrition, lack of hygiene, bruising of the limbs, wearing inappropriate clothing, etc. with no scoring. In contrast, the VASS questionnaire is easily completed by the elderly in any situation (hospitalized or at home) and has easy scoring and evaluation [20].

The Caregiver Abuse Screen for the Elderly (CASE) questionnaire in 1995 and Indicators of Abuse (IOA) questionnaire in 1998 were designed by Reis et al. in Canada. These tools measure the likelihood of an elder being abused by the caregiver and are only applicable to the elderly who have a caregiver $[54,55]$. The E-IOA Elder Abuse Index is an extended version of the IOA designed by Cohen et al. [56]. This tool can be used to screen hospitalized elderly individuals. The questions are completed by a trained professional, and the evaluation time is approximately 2 hours, which is one of the limitations of this tool [56], whereas the elderly evaluation time was estimated to be about 5 minutes using the VASS.

\section{Conclusions}

According to the study results and the advantages of VASS over other existing questionnaires to screen for abuse with good validity and reliability, this tool can be applied in future research in Iranian communities to identify victims of abuse and should be provided, designed and implemented in nursing interventions and related programs in the field of family care to prevent elder abuse and improve understanding of this social challenge.

Acknowledgements. This study was extracted from a master thesis in nursing, which was conducted at Shahroud University of Medical Sciences. This research was approved by the university under the code 95168 . The authors would like to thank the elderly people who helped us in this research. 
Source of funding: This work was funded from the authors' own resources.

Conflicts of interest: The authors declare no conflicts of interest.

\section{References}

1. WHO. World report on ageing and health. Geneva: World Health Organization; 2015.

2. Yon Y, Mikton CR, Gassoumis ZD, et al. Elder abuse prevalence in community settings: a systematic review and meta-analysis. Lancet Glob Health 2017; 5(2): e147-e156.

3. Mehri N, Messkoub M, Kunkel S. Trends, determinants and the implications of population aging in Iran. Ageing Int 2020; 45(4): 327$-343$.

4. Fakoya OO, Abioye-Kuteyi EA, Bello IS, et al. Determinants of quality of life of elderly patients attending a general practice clinic in Southwest Nigeria. Int Q Community Health Educ 2018; 39(1): 3-7.

5. Acierno R, Hernandez MA, Amstadter AB, et al. Prevalence and correlates of emotional, physical, sexual, and financial abuse and potential neglect in the United States: the National Elder Mistreatment Study. Am J Public Health 2010; 100(2): 292-297.

6. Amstadter AB, Zajac K, Strachan M, et al. Prevalence and correlates of elder mistreatment in South Carolina: the South Carolina elder mistreatment study. J Interpers Violence 2011; 26(15): 2947-2972.

7. Sooryanarayana R, Choo W-Y, Hairi NN. A review on the prevalence and measurement of elder abuse in the community. Trauma Violence Abuse 2013; 14(4): 316-325.

8. Chalise HN, Paudel BR. Elderly abuse among community-living older adults of least developed country - Nepal. Arch Phys Rehabil Med 2020; 1(1): 1-8.

9. Honarvar B, Gheibi Z, Asadollahi A, et al. The impact of abuse on the quality of life of the elderly: a population-based survey in Iran. J Prev Med Public Health 2020; 53(2): 89-97.

10. Clancy M, McDaid B, O'neill D, et al. National profiling of elder abuse referrals. Age Ageing 2011; 40(3): 346-352.

11. Lachs MS, Pillemer KA. Elder abuse. N Engl J Med 2015; 373(20): 1947-1956.

12. Molaei M, Etemad K, Taheri Tanjani P. Prevalence of elder abuse in Iran: a systematic review and meta analysis. Iran J Ageing 2017; 12(2): 242-253.

13. Yon Y, Mikton C, Gassoumis ZD, et al. The prevalence of self-reported elder abuse among older women in community settings: a systematic review and meta-analysis. Trauma Violence Abuse 2019; 20(2): 245-259.

14. Bennett G, Kingston P. Elder abuse: theories, concepts and interventions. London: Chapman and Hall; 1993.

15. Alizadeh-Khoei M, Sharifi F, Hossain SZ, et al. Elder abuse: risk factors of abuse in elderly community-dwelling Iranians. Educ Gerontol 2014; 40(7): 543-554.

16. Mouton CP, Rodabough RJ, Rovi SL, et al. Prevalence and 3-year incidence of abuse among postmenopausal women. Am J Public Health 2004; 94(4): 605-612.

17. Mouton CP, Southerland JH. Elder abuse in the African Diaspora: a review. J Natl Med Assoc 2017; 109(4): 262-271.

18. Naderi Z, Gholamzadeh S, Zarshenas L, et al. Psycho-emotional consequences of hospitalized elder abuse from older patients' perspective. Electron J Gen Med 2020; 17(2): em194, doi.org/10.29333/ejgm/7811.

19. Fulmer T, Paveza G, Abraham I, et al. Elder neglect assessment in the emergency department. J Emerg Nurs 2000; 26(5): 436-443.

20. Yaffe MJ, Wolfson C, Lithwick M, et al. Development and validation of a tool to improve physician identification of elder abuse: the Elder Abuse Suspicion Index (EASI) ${ }^{\odot}$. J Elder Abuse Negl 2008; 20(3): 276-300.

21. Mokkink LB, Terwee CB, Patrick DL, et al. COSMIN checklist manual. Amsterdam: University Medical Center; 2012.

22. Heravi-Karimooi $M$, Anoosheh $M$, Foroughan $M$, et al. Designing and determining psychometric properties of the Domestic Elder Abuse Questionnaire. Iran J Ageing 2010; 5(1). Available from URL: http://salmandj.uswr.ac.ir/article-1-290-en.html.

23. Schofield MJ, Mishra GD. Validity of self-report screening scale for elder abuse: Women's Health Australia Study. Gerontologist 2003; 43(1): 110-120.

24. Schofield MJ, Reynolds R, Mishra GD, et al. Screening for vulnerability to abuse among older women: Women's Health Australia Study. J Appl Gerontol 2002; 21(1): 24-39.

25. Aşiret GD, Bağçivan G, Özcan M, et al. Cross-cultural adaptation and psychometric assessment of the Turkish version of the Vulnerability to Abuse Screening Scale. Turk J Med Sci 2017; 47(4): 1223-1228.

26. Dantas RB, Oliveira GL, Silveira AM. Psychometric properties of the Vulnerability to Abuse Screening Scale for screening abuse of older adults. Rev Saude Publica 2017; 51: 31, doi: 10.1590/S1518-8787.2017051006839.

27. Grenier F, Capriz F, Lacroix-Hugues V, et al. Evaluation of French version of the Vulnerability to abuse screen scale (VASS), a elder abuse screening tool. Geriatr Psychol Neuropsychiatr Vieil 2016; 14(2): 142-150, doi: 10.1684/pnv.2016.0595.

28. Grenier F, Capriz F, Lacroix-Hugues V, et al. Évaluation du Vulnerability to abuse screen scale (VASS), version française d'un test de dépistage de la maltraitance du sujet âgé. Gériatrie et Psychologie Neuropsychiatrie du Vieillissement 2016; 14(2): $142-150$ (in French).

29. Maia RS, Maia EMC. Brazilian Portuguese cross-cultural adaptation of the Vulnerability to Abuse Screening Scale (VASS) for screening of violence against the elderly. Cad Saude Publica 2014; 30(7): 1379-1384.

30. Maia RS, Maia EMC. Psychometric evidence of the transcultural adaptation of the Vulnerability Abuse Screening Scale (VASS) for the detection of violence against the elderly. Rev Bras Geriatr Gerontol 2016; 19(6): 958-969.

31. Özçakar N, Ergönen AT, Kartal M, et al. Adaptation, reliability, and validity study of the Hwalek-SengstockElder Abuse Screening Test (HS/EAST): a Turkish version. Turk J Med Sci 2017; 47(6): 1894-1902.

32. Dong X, Simon MA. Is greater social support a protective factor against elder mistreatment? Gerontology 2008; 54(6): 381-388.

33. Dong X, Simon MA, Gorbien M, et al. Loneliness in older Chinese adults: a risk factor for elder mistreatment. J Am Geriatr Soc 2007; 55(11): 1831-1835.

34. Dong X, Wang B. Incidence of elder abuse in a US Chinese population: findings from the longitudinal cohort PINE Study. J Gerontol Series A 2017; 72(Suppl_1): S95-S101.

35. Laumann EO, Leitsch SA, Waite LJ. Elder mistreatment in the United States: prevalence estimates from a nationally representative study. J Gerontol B Psychol Sci Soc Sci 2008; 63(4): S248-S254.

36. Li M, Liang Y, Dong X. Different definitions of elder mistreatment and mortality: a prospective cohort study from 2011 to 2017. J Am Geriatr Soc 2019; 67(S3): S506-S512.

37. Luo Y, Waite LJ. Mistreatment and psychological well-being among older adults: exploring the role of psychosocial resources and deficits. J Gerontol B Psychol Sci Soc Sci 2011; 66(2): 217-229. 
38. Maia R, Cavalcanti A, Maia E. Violence against the elderly: correlation with social support, depressive symptoms and sociodemographic characterization of an elderly population of the Brazilian Northeast. MOJ Gerontol Ger 2018; 3(6): 446-448.

39. Mehra A, Grover S, Agarwal A, et al. Prevalence of elder abuse and its association with psychiatric morbidity in a rural setting. I Neurosci Rural Pract 2019; 10(2): 218-224.

40. Schofield MJ, Powers JR, Loxton D. Mortality and disability outcomes of self-reported elder abuse: a 12-year prospective investigation. J Am Geriatr Soc 2013; 61(5): 679-685.

41. Wu L, Chen H, Hu Y, et al. Prevalence and associated factors of elder mistreatment in a rural community in People's Republic of China: a cross-sectional study. PLOS ONE 2012; 7(3): e33857.

42. Folstein MF, Folstein SE, McHugh PR. "Mini-mental state": a practical method for grading the cognitive state of patients for the clinician. J Psychiatr Res 1975; 12(3): 189-198.

43. Jitapunkul S, Pillay I, Ebrahim S. The abbreviated mental test: its use and validity. Age Ageing 1991; 20(5): 332-336.

44. Arafat SY, Chowdhury HR, Qusar M, et al. Cross cultural adaptation \& psychometric validation of research instruments: a methodological review. J Behav Health 2016; 5(3): 129-136.

45. Polit DF, Beck CT. Measurement and data quality. Essentials of nursing research: appraising evidence for nursing practice. Philadelphia: Lippincott Williams \& Wilkins; 2009: 377-379.

46. Polit DF, Beck CT. The content validity index: are you sure you know what's being reported? Critique and recommendations. Res Nurs Health 2006; 29(5): 489-497.

47. Lawshe CH. A quantitative approach to content validity 1. Pers Psychol 1975; 28(4): 563-575.

48. Waltz CF, Bausell BR. Nursing research: design statistics and computer analysis. Philadelphia: F.A. Davis Co., 1981.

49. Baumgartner TA, Chung H. Confidence limits for intraclass reliability coefficients. Meas Phys Educ Exerc Sci 2001; 5(3): 179-188.

50. Polit DF, Beck CT. Measurement and data quality, essentials of nursing research: appraising evidence for nursing practice. Philadelphia: Lippincott Williams \& Wilkins; 2009.

51. Pett MA, Lackey NR, Sullivan JJ. Making sense of factor analysis: the use of factor analysis for instrument development in health care research. Thousand Oaks: Sage Publications; 2003.

52. Akaike H. A new look at the statistical model identification. In: Parzen E, Tanabe K, Kitagawa G, eds. Selected papers of Hirotugu Akaike. Springer Series in Statistics (Perspectives in Statistics). New York (NY): Springer: 215-222.

53. Schwarz G. Estimating the dimension of a model. Ann Stat 1978; 6(2): 461-464.

54. Reis M, Nahmiash D. Validation of the caregiver abuse screen (CASE). Can J Aging 1995; 14(S2): 45-60.

55. Reis M, Nahmiash D. Validation of the indicators of abuse (IOA) screen. Gerontologist 1998; 38(4): 471-480.

56. Cohen M, Halevi-Levin S, Gagin R, et al. Development of a screening tool for identifying elderly people at risk of abuse by their caregivers. J Aging Health 2006; 18(5): 660-668.

Tables: 3

Figures: 1

References: 56

Received: 11.07.2020

Reviewed: 29.07 .2020

Accepted: 1.09 .2020

Address for correspondence:

Hossein Ebrahimi, PhD

Center for Health Related Social and Behavioral Sciences Research

Shahroud University of Medical Sciences

7th Square

Postal code: 3614773955

Shahroud

Iran

Tel: +982332393811

E-mail: ebrahimi@shmu.ac.ir 